
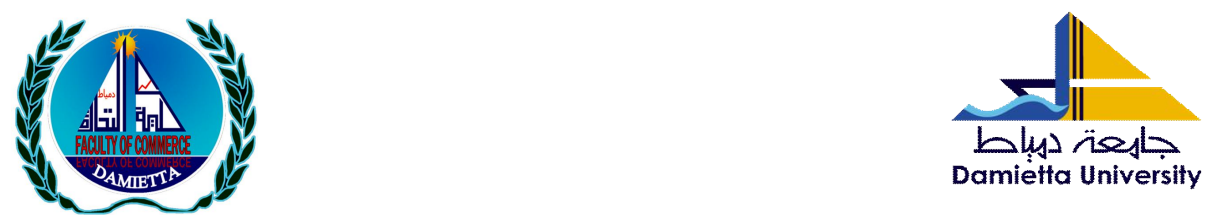

\title{
Horizontal and vertical Aggregation Bias of time series with empirical study
}

\author{
Prepared 6y \\ Samar Ahmed Helmy Abdelghany \\ Lecturer, Department of Statistics, Mathematics \& Insurance \\ Faculty of Commerce, Port Said University \\ blue arkedia@hotmail.com
}

Scientific Journal for Financial and Commercial Studies and Researches (SIFCSR)

Faculty of Commerce - Damietta University

Vol.3, No.1, Part 1., January 2022

APA Citation:

Abdelghany, S. A. H. (2022). Horizontal and vertical Aggregation Bias of time series with empirical study, Scientific Journal for Financial and Commercial Studies and Research, Faculty of Commerce, Damietta University, 3(1)1, pp. 397-428.

Website: https://cfdi.journals.ekb.eg/ 
Scientific Journal for Financial and Commercial Studies and Researches

(SJFCSR) Faculty of Commerce - Damietta University

\title{
Horizontal and vertical Aggregation Bias of time series with empirical study
}

\author{
Samar Ahmed Helmy Abdelghany
}

\begin{abstract}
Aggregation bias is defined (Theil 1954) as the difference between the macro parameter and the average of the micro parameters. In this article, a new definition of time series aggregation is introduced. Imperially, a new definition of aggregation bias is introduced. Using the new definition, the time series are aggregated in two different methods, horizontal and vertical. Bias resulting from this aggregation is analyzed in both cases. Horizontal aggregation revealed unbiasedness in the slope and intercept of the trend of the series. Vertical aggregation revealed bias in estimating both parameters of the trend of the series depending on the length of the aggregation period. A new theorem "Samar theorem" is introduced to assess bias in both parameters. Proof of the Samar theorem is annexed to the paper. An Empirical study containing data of a number of time series are analyzed in the frame of the new theorem. The data is the weekly income of some Egyptian farmers working on the same farm collected through an Egyptian agrarian year. Samar theorem introduce rules to compute bias in the slope and the intercept of the trend of the series. It also shows the relation between the two biases. In addition, the effect of the length of aggregation period on the amount of bias is discussed.
\end{abstract}

Key words: Aggregation bias, Egyptian agrarian year, Trend, Samar theorem 


\section{Introduction}

Moorman (1979) stated that any discussion of aggregation bias necessarily begins with Robinson's (1950) well-known article; "Ecological Correlation and the Behavior of Individuals"; Since that article, there has been considerable discussion of the ecological fallacy, but little attempt to actually measure the amount of bias introduced by aggregation of individuals into areal units when data existed at both levels.

Albuquerque (2003) showed that the exact aggregate representation derived is relatively simple and intuitive. It can be used thereafter in applied issues and in teaching, easing the solving and understanding of aggregation problems.

Franta (2008) focused in his paper on the dynamics of unemployment in the Czech Republic over the period 1992-2007. Unemployment dynamics are elaborated in terms of unemployment inflows and unemployment duration. The paper contributes to the literature dealing with discrete time models of aggregate unemployment duration data by accounting for time aggregation bias.

Sbrana (2011) derived the analytical relationships between structural and reduced form parameters of the local linear trend model with correlated shocks. The results are also valid in the context of temporal aggregation of local level and local linear trend models with their corresponding $\operatorname{ARIMA}(0,1,1)$ and $\operatorname{ARIMA}(0,2,2)$ reduced forms.

Many research work focused on different aspects of aggregation. Little attention was given to aggregation bias in time series. This article sheds some light on the issue.

\subsection{Definition of aggregation bias}

Aggregation bias is defined according to Theil (1954) as the difference between the macro parameter and the average of the micro parameter. For example, the following single equation model can be expressed as:

$$
Y_{i j}=\alpha_{j}+\beta_{1 i} X_{1 i j}+\beta_{2 i} X_{2 i j}+\ldots .+\beta_{k i} X_{k i j}+e_{i j}
$$


Where:

$$
\begin{aligned}
& i=1,2, \ldots, I \quad \text { number of equations } \\
& j=1,2, \ldots, n \quad \text { number of observations } \\
& k=\quad \text { number of explanatory variables }
\end{aligned}
$$

The model is aggregated over i so the macro relation becomes

$$
\sum_{i=1}^{I} Y_{i j}=\mathrm{A}+\mathrm{B}_{1} \sum_{i=1}^{I} X_{1 i j}+\mathrm{B}_{2} \sum_{i=1}^{I} X_{2 i j}, \ldots .,+\mathrm{B}_{k} \sum_{i=1}^{I} X_{k i j}+E_{j}
$$

Notice that all variables, dependent or independent, are aggregated.

\subsection{Time series}

As known, a time series is a collection of observations of welldefined data items obtained through repeated measurements over time. For example, measuring the amount of weekly income of a person would comprise a time series. This is because personal income is well defined, and consistently measured at equally spaced intervals.

An observed time series may be decomposed into four components: the Secular Trend (Trend), the (Seasonal Variations), the (Cyclical Variations) and the (Irregular Variations)

The study focuses on the trend only

\subsection{Types of aggregating time series}

The functional form of the time series is $Y=f(T)$ where $T$ is the time. If we have (n) observations on a number (I) of time series, we have:

$\mathrm{Y}_{\mathrm{iT}}=\alpha_{\mathrm{j}}+\beta_{\mathrm{i}} \mathrm{T}+\mathrm{e}_{\mathrm{iT}}$

$$
\mathrm{T}=1,2, \ldots ., \mathrm{n}, \mathrm{i}=1, \ldots, \mathrm{I}
$$

Equation (1.3) is aggregated horizontally as follows:

$$
\sum_{i=1}^{I} Y_{i T}=\mathrm{A}+\mathrm{B} T+E \quad \mathrm{~T}=1,2, \ldots ., \mathrm{n}
$$

Notice that only the dependent variable is aggregated, where $T$, the independent variable is not aggregated. This is a crucial difference than that in (1.1) which implies different definition of aggregation bias. 


\section{Samar Ahmed Helmy Abdelghany}

Aggregation bias of time series depends on the method of aggregation. Time series is aggregated in two different methods:

a - Contemporaneous Aggregation (Cross Sectional Aggregation) i.e aggregating some variables in the same time, e.g data necessary to establish an index number. As for time series it means aggregating a number of time series, equation (1.3), to form one series so the aggregated series will be equation (1.4). This type of aggregation will be called horizontal aggregation

b - Temporal Aggregation means aggregation on the same series, i.e grouping the observations to a new timely series, e.g aggregating weekly data to form monthly data. This type of aggregation will be called vertical aggregation. Let:

$$
Z_{X}=\sum_{j=1}^{k} Y_{k X-k+j}, E_{X}=\sum_{j=1}^{k} e_{k X-k+j}, X=1, \ldots, n / k, j=1, \ldots, k
$$

Where $\mathrm{k}$ is the number of observations added together, so $\mathrm{k}=4$ if quarterly data are converted into yearly data or $\mathrm{k}=12$ if the detailed data were monthly .... etc.

Then the aggregated equation will

$$
\mathrm{Z}_{\mathrm{X}}=\mathrm{A}+\mathrm{BX}+\mathrm{E}_{\mathrm{X}} \quad X=1, \ldots, n / k
$$

\section{Calculation of aggregation bias of time series}

To calculate the aggregation bias, the following steps are followed:

a. Estimate the parameters of the detailed equation using a suitable estimation method

b. Estimate the parameters of the aggregated equation using the same estimation method

c. The aggregation bias in the parameters of the time series can be represented for horizontal aggregation as

Bias in the slope $\quad=\mathrm{B}-\sum_{i=1}^{I} \beta_{i}$ 
Bias in the intercept $=\mathrm{A}-\sum_{i=1}^{I} \alpha_{i}$

That is, bias will be the difference between the aggregated parameter and the sum of individual parameters. For example, if the monthly increase in the income of a person is L.E 20 and that of another person is 30 so the aggregated increase will be L.E 50. The same argument applies to the intercept.

For convenience, if we use deviations from the related mean of the variables of (1.3), it becomes

$y_{i x}=\beta_{i} x+e_{i x} \quad, i=1, \ldots, I, x=1, \ldots, n$

Where: $y_{i x}=Y_{i x}-\bar{Y}_{i}$

$$
, i=1, \ldots, I
$$

$$
\begin{aligned}
& x=T-\bar{T} \quad(x \text { is the same in all series }) \\
& e_{x}=e_{x}-\bar{e}=e_{x}-0=e_{x}
\end{aligned}
$$

$\mathrm{n} \quad$ is the number of observations on time $\mathrm{x}$

The OLS estimator of $\beta$ is

$$
\hat{\beta}_{i}=\frac{\sum_{x=1}^{n} y_{x} x}{\sum_{x=1}^{n} x^{2}} \quad i=1, \ldots, I, x=1, \ldots, n
$$

, the estimator of $\alpha$ is

$$
\hat{\alpha}_{i}=\bar{Y}_{i}-\hat{\beta}_{i} \bar{T} \quad i=1, \ldots, I \quad \bar{T} \text { is the same in all series (2.5) }
$$

and the estimated trend is

$$
\hat{Y}_{i}=\hat{\alpha}_{i}+\hat{\beta}_{i} T
$$




\subsection{Bias in the slope and intercept in the horizontal aggregation}

For convenience, consider two time series in the deviated form:

$$
\begin{array}{ll}
y_{1 x}=\beta_{1} x+e_{1 x} & , x=1, \ldots, n \\
y_{2 x}=\beta_{2} x+e_{2 x} & , x=1, \ldots, n
\end{array}
$$

the horizontal aggregation of (2.7) and (2.8) is:

$$
z_{x}=\mathrm{B} x+E_{x} \quad, x=1, \ldots, n
$$

Where :

$$
\begin{array}{ll}
z_{x} & \text { is the sum of the two series } \quad z_{x}=y_{1 x}+y_{2 x} \\
x & \text { time deviations } \\
E_{x} & \text { sum of error in the two series } E_{x}=e_{1 x}+e_{2 x} \\
n & \text { number of observations }
\end{array}
$$

Estimator of the aggregated slope is:

$$
\hat{\mathrm{B}}=\frac{\sum_{x=1}^{n} z_{x} x}{\sum_{x=1}^{n} x^{2}}
$$

Estimator of the aggregated intercept is:

$$
\hat{\mathrm{A}}=\bar{Z}-\hat{\mathrm{B}} \bar{T}
$$

By definition of the aggregation bias in the slope, of equation (2.9)

$\operatorname{Bias}(\hat{\mathrm{B}})=\hat{\mathrm{B}}-\left(\hat{\beta}_{1}+\hat{\beta}_{2}\right)$

and the aggregation bias in the intercept, of equation (2.9)

$\operatorname{Bias}(\hat{\mathrm{A}})=\hat{\mathrm{A}}-\left(\hat{\alpha}_{1}+\hat{\alpha}_{2}\right)$ 
To derive the bias in the slope, substitute in (2.12)

$\operatorname{Bias}(\hat{\mathrm{B}})=\frac{\sum_{t=1}^{n} z_{t} x_{t}}{\sum_{x=1}^{n} x^{2}}-\left[\frac{\sum_{x=1}^{n} y_{1 x} x}{\sum_{x=1}^{n} x^{2}}+\frac{\sum_{x=1}^{n} y_{2 x} x}{\sum_{x=1}^{n} x^{2}}\right]$

$$
=\frac{\sum_{t=1}^{n} z_{t} x_{t}-\left[\sum_{x=1}^{n} y_{1 x} x+\sum_{x=1}^{n} y_{2 x} x\right]}{\sum_{x=1}^{n} x^{2}}
$$

sustitute $\quad \mathrm{z}_{\mathrm{x}}=\mathrm{y}_{1 \mathrm{x}}+\mathrm{y}_{2 \mathrm{x}}$

$$
\begin{aligned}
\operatorname{Bias}(\hat{\mathrm{B}})=\frac{\sum_{x=1}^{n}\left(y_{1 x}+y_{2 x}\right) x-\left[\sum_{x=1}^{n} y_{1 x} x+\sum_{x=1}^{n} y_{2 x} x\right]}{\sum_{t=1}^{n} x_{t}^{2}} \\
=\frac{\sum_{x=1}^{n} y_{1 x} x+\sum_{x=1}^{n} y_{2 x} x-\left[\sum_{x=1}^{n} y_{1 x} x+\sum_{x=1}^{n} y_{2 x} x\right]}{\sum_{x=1}^{n} x^{2}}=\frac{0}{\sum_{t=1}^{n} x_{t}^{2}}=0
\end{aligned}
$$

Then horizontal aggregation of time series does not result in aggregation bias in the slope

To derive aggregation bias in the intercept, substitute in (2.13)

$$
\begin{array}{ll}
\operatorname{Bias}(\hat{\mathrm{A}}) \quad=\quad \hat{\mathrm{A}}-\left(\hat{\alpha}_{1}+\hat{\alpha}_{2}\right) & \\
= & (\bar{Z}-\hat{\mathrm{B}} \bar{T})-\left[\left(\bar{Y}_{1}-\hat{\beta}_{1} \bar{T}\right)+\left(\bar{Y}_{2}-\hat{\beta}_{2} \bar{T}\right)\right] \\
& =\bar{Z}-\hat{\mathrm{B}} \bar{T}-\bar{Y}_{1}+\hat{\beta}_{1} \bar{T}-\bar{Y}_{2}+\hat{\beta}_{2} \bar{T} \\
\operatorname{since} Z=Y_{1}+ & Y_{2} \Rightarrow \bar{Z}=\bar{Y}_{1}+\bar{Y}_{2} \quad \Rightarrow \quad \bar{Z}-\bar{Y}_{1}-\bar{Y}_{2}=0 \\
\operatorname{Bias}(\hat{\mathrm{A}}) \quad= & -\hat{\mathrm{B}} \bar{T}+\hat{\beta}_{1} \bar{T}+\hat{\beta}_{2} \bar{T}=\bar{T}\left(\hat{\beta}_{1}+\hat{\beta}_{2}-\hat{\mathrm{B}}\right)
\end{array}
$$


Substitute for the slopes

$\operatorname{Bias}(\hat{\mathrm{A}})=\bar{T}\left(\left[\frac{\sum_{x=1}^{n} y_{1 x} x}{\sum_{x=1}^{n} x^{2}}+\frac{\sum_{x=1}^{n} y_{2 x} x}{\sum_{x=1}^{n} x^{2}}\right]-\frac{\sum_{t=1}^{n} z_{t} x_{t}}{\sum_{x=1}^{n} x^{2}}\right)$

using (2.14)

$\operatorname{Bias}(\hat{\mathrm{A}}) \quad \bar{T}(0)=0$

Also, horizontal aggregation of time series does not result in bias in the intercept. Since $\hat{\mathrm{A}}=\bar{Z}-\hat{\mathrm{B}} \bar{T}$ as $\bar{Z}$ and $\bar{T}$ are constants, so if $\hat{\mathrm{B}}$ is bias free, then $\hat{A}$ should be bias free too.

Then we conclude that horizontal aggregation does not result in any bias in the parameters of the series.

\subsection{Bias in the slope and intercept in the vertical aggregation}

To establish a reference criterion to calculate the aggregation bias, an algebraic series, i.e error free, is vertically aggregated with different periods of aggregation $\mathrm{k}$. For the series

$$
Y_{T}=13+3 T \quad, \mathrm{~T}=1, \ldots, 60
$$

the intercept $\alpha \quad 13=$ and the slope $\beta=3$. Linear regression using SPSS on data with different periods of aggregation $k$, starting with $k=2$, can be shown as in table (1) 
Scientific Journal for Financial and Commercial Studies and Researches (SJFCSR) Faculty of Commerce - Damietta University

\section{Table (1)}

Coefficients of the algebraic equation $Y_{T}=13+3 T$ aggregated

$$
\text { on period } k=2
$$

Coefficients $^{\mathrm{a}}$

\begin{tabular}{|cc|c|c|c|c|c|}
\hline \multirow{2}{*}{ Model } & \multicolumn{2}{|c|}{$\begin{array}{c}\text { Unstandardized } \\
\text { Coefficients }\end{array}$} & \multicolumn{2}{c|}{$\begin{array}{c}\text { Standardized } \\
\text { Coefficients }\end{array}$} & \multirow{2}{*}{$\mathrm{t}$} & \multirow{2}{*}{ Sig. } \\
\cline { 2 - 5 } & $\mathrm{B}$ & Std. Error & Beta & & \\
\hline \multirow{2}{*}{1} & (Constant) & 23.000 & .000 & &. & . \\
& $\mathrm{k}=2$ & 12.000 & .000 & 1.000 &. &. \\
\hline
\end{tabular}

a. Dependent Variable: Aggregated 2

of course, there is no error and the result is

$$
\mathrm{Z}_{\mathrm{x}}=23+12 \mathrm{X} \quad, \mathrm{x}=1, \ldots, 30(\mathrm{n} / \mathrm{k})
$$

the slope $\mathrm{B}(\mathrm{k})$ is

$$
\mathrm{B}(2)=12=3 \times(2 \times 2)=\beta \mathrm{k}^{2}
$$

the intercept $\mathrm{A}(\mathrm{k})$ is $\mathrm{A}(2)=23$

when $\mathrm{k}=3$ the result is

$$
\mathrm{H}_{\mathrm{R}}=30+27 \mathrm{R} \quad, \mathrm{R}=1, \ldots, 20(n / k)
$$

the slope $\mathrm{B}(\mathrm{k})$ is

$$
\mathrm{B}(3)=27=3 \times(3 \times 3)=\beta \mathrm{k}^{2}
$$

the intercept $\mathrm{A}(\mathrm{k})$ is $\mathrm{A}(3)=30$

with $k=4$ the result is

$$
\mathrm{M}_{\mathrm{Q}}=34+48 \mathrm{Q} \quad, \mathrm{Q}=1, \ldots, 15(n / k)
$$


Samar Ahmed Helmy Abdelghany

the slope $\mathrm{B}(\mathrm{k})$ is

$$
\mathrm{B}(4)=48=3 \times(4 \times 4)=\beta \mathrm{k}^{2}
$$

the intercept $\mathrm{A}(\mathrm{k})$ is $\mathrm{A}(4)=34$

with $k=5$ the result is

$$
\mathrm{S}_{\mathrm{V}}=35+75 \mathrm{~V} \quad, \mathrm{~V}=1, \ldots, 12(\mathrm{n} / \mathrm{k})
$$

the slope $\mathrm{B}(\mathrm{k})$ is

$$
\mathrm{B}(5)=75=3 \times(5 \times 5)=\beta \mathrm{k}^{2}
$$

the intercept $\mathrm{A}(\mathrm{k})$ is $\mathrm{A}(5)=35$

Generally, aggregating on a period $k$, the detailed equation is

$$
Y_{t}=\alpha+\beta T+e_{t} \quad, T=1, \ldots, n
$$

taking

$Z_{X}(k)=\sum_{j=1}^{k} Y_{k X-k+j}, E_{X}(k)=\sum_{j=1}^{k} e_{k X-k+j}, X=1, \ldots, n / k, j=1, \ldots, k$

the aggregated equation will be

$$
Z_{X}=\mathrm{A}+\mathrm{B} X(k)+E_{X}, X=1, \ldots, n / k
$$

The slope

$$
\mathrm{B}=\frac{\sum_{X=1}^{n / k}\left(Z_{X}-\bar{Z}_{X}\right)(X(k)-\bar{X}(k))}{\sum_{X=1}^{n / k}(X(k)-\bar{X}(k))^{2}}, X=1, \ldots, n / k
$$

and the intercept

$$
\mathrm{A}=\bar{Z}-\mathrm{B} \bar{X}
$$

Hint: we used $\mathrm{A}$ and $\mathrm{B}$ rather than $\hat{\mathrm{A}}$ and $\hat{\mathrm{B}}$ since the detailed and aggregated equations are perfect, i.e error free 
To study the effect of aggregation on the intercept, we need the following relations:

a - The relation between $\bar{Y}, \bar{Z}$ :

The sum of all observations $\mathrm{Y}_{\mathrm{t}}=\sum_{t=1}^{n} Y_{t}$, also $=\sum_{t=1}^{n / k} Z_{t}$ since the vertical aggregation has no effect on the sum of all observations, then

$$
\bar{Z}=\frac{\sum_{t=1}^{n / k} Z_{t}}{n / k}=\frac{\sum_{t=1}^{n} Y_{t}}{n / k}=k \frac{\sum_{t=1}^{n} Y_{t}}{n}=k \bar{Y}
$$

$\mathrm{b}$ - The relation between the mean of detailed time $\bar{T}$ and the mean of aggregated time $\bar{X}$

The detailed time $\mathrm{T}$ is an arithmetic progression with first term 1 and the last term $n$, its sum $=\frac{n}{2}(1+n)$ and its mean $\bar{T}=\frac{1}{2}(1+n)$

Where the time $X(\mathrm{k})$ aggregated on period $k$, is an arithmetic progression with first term 1 and the last tem $n / k$, its sum $=$ $\frac{n / k}{2}(1+n / k)$ and its mean $\bar{X}=\frac{1}{2}(1+n / k)$

Now, the intercept of the aggregated equation is $\mathrm{A}=\bar{Z}-\mathrm{B} \bar{X}(k)$

Hint : $\bar{X}=\bar{T}$ when $k=1$

$$
\mathrm{A}=k \bar{Y}-\beta k^{2}\left[\frac{1}{2}(1+n / k)\right]=k\left[\bar{Y}-\frac{1}{2} \beta(n+k)\right]
$$




\section{Samar Ahmed Helmy Abdelghany}

The mean of the detailed equation $\bar{Y}=104.5$

Applying the rule (2.33) on equation (2.18), $\mathrm{k}=2$ where $\mathrm{A}=23$

$$
\mathrm{A}=k\left[\bar{Y}-\frac{1}{2} \beta(n+k)\right]=2[104,5-0,5(3)(62)]=2(104.5-93)=23
$$

Applying the rule (2.33) on equation (2.21), $\mathrm{k}=3$ where $\mathrm{A}=30$

$$
\mathrm{A}=k\left[\bar{Y}-\frac{1}{2} \beta(n+k)\right]=3[104,5-0,5(3)(63)]=3(104.5-94,5)=30
$$

Applying the rule (2.33) on equation (2.24), $\mathrm{k}=4$ the intercept $\mathrm{A}=34$

$$
\mathrm{A}=k\left[\bar{Y}-\frac{1}{2} \beta(n+k)\right]=4[104,5-0,5(3)(64)]=4(104.5-96)=34
$$

Applying the rule (2.33) on equation (2.27), $\mathrm{k}=5$ the intercept $\mathrm{A}=35$

$$
\mathrm{A}=k\left[\bar{Y}-\frac{1}{2} \beta(n+k)\right]=5[104,5-0,5(3)(65)]=5(104.5-96)=35
$$

Equations (2.19), (2.22), (2.25), and (2.28) and realization of the intercept above, prove the following Samar theorem:

\section{Samar theorem}

\section{Parameters of aggregated time series}

The parameters of aggregated time series depend on aggregation method as follows:

\section{Part (1) : Horizontal aggregation}

Given a number I of time series:

$$
\mathrm{Y}_{\mathrm{iT}}=\alpha_{\mathrm{j}}+\beta_{\mathrm{i}} \mathrm{T}+\mathrm{e}_{\mathrm{iT}} \quad \mathrm{T}=1,2, \ldots, \mathrm{n}, \mathrm{i}=1, \ldots, \mathrm{I}
$$


it can be aggregated horizontally as follows:

$\sum_{i=1}^{I} Y_{i T}=\mathrm{A}+\mathrm{B} T+\sum_{i=1}^{I} e_{i T}$

then the slope $\mathrm{B}(\mathrm{I})=\sum_{i=1}^{I} \beta_{i}$ and intercept $\mathrm{A}(\mathrm{I})=\sum_{i=1}^{I} \alpha_{i}$

do not imply any bias for any number of time series

\section{Part (2) : Vertical aggregation:}

Given a time series $\mathbf{Y}$

$\mathrm{Y}_{\mathrm{T}}=\alpha+\beta \mathrm{T}+\mathrm{e}_{\mathrm{T}} \quad \mathrm{T}=1,2, \ldots, \mathrm{n}$

aggregated vertically on a time period $\boldsymbol{k}$ (positive number $<\mathrm{n}$ ) as follows:

$\mathrm{Z}_{\mathrm{X}}(\mathrm{k})=\mathrm{A}(\mathrm{k})+\mathrm{B}(\mathrm{k}) \mathrm{X}(\mathrm{k})+\mathrm{E}_{\mathrm{X}}(\mathrm{k})$

where

$Z_{X}(k)=\sum_{j=1}^{k} Y_{k X-k+j}, E_{X}(k)=\sum_{j=1}^{k} e_{k X-k+j}, X=1, \ldots, n / k, j=1, \ldots, k$

Then the aggregated slope $\mathbf{B}(\mathbf{k})=\boldsymbol{\beta} \boldsymbol{k}^{2} \quad$ and

Aggregated intercept $\mathbf{A}(\mathbf{k})=k\left[\bar{Y}-\frac{1}{2} \beta(n+k)\right]$

Condition that aggregation does not result in any bias.

\section{Corollary (1)}

If the condition of vertical aggregation of Samar is violated, then:

Aggregation bias in the slope is $\quad \mathbf{S}_{\boldsymbol{\beta}}(\mathbf{k})=\mathbf{B}(\mathbf{k})-\mathbf{k}^{2} \boldsymbol{\beta} \quad$ and

Aggregation bias in the intercept is $\mathbf{S}_{\boldsymbol{a}}(\mathbf{k})=\mathbf{A}(\mathbf{k})-k\left[\bar{Y}-\frac{1}{2} \beta(n+k)\right]$

where: $\mathrm{B}(\mathrm{k})$ is the slope of the aggregated series on period $\mathrm{k}$ 
Samar Ahmed Helmy Abdelghany

$\mathrm{A}(\mathrm{k})$ is the intercept of the aggregated series on period $\mathrm{k}$

$\bar{Y}$ is the mean of detailed series

$\beta$ is the slope of detailed series

$\mathrm{n}$ is the number of observations of detailed series

$\mathrm{k}$ is the aggregation period

\section{Corollary (2)}

Aggregation bias in the slope $\mathbf{S}_{\boldsymbol{\beta}}(\mathbf{k})$ results in aggregation bias in the intercept $\mathbf{S}_{\mathbf{a}}(\mathbf{k})$ since

$A(k)=\bar{Z}(k)-B(k) \bar{X}(k) \quad$ where

$\bar{Z}(k)$ is the mean of the aggregated observations

$\bar{X}(k)$ is the mean of the time sequence of the aggregated series

are fixed do not imply any bias

\section{Corollary (3)}

The bias $\mathbf{S}_{\boldsymbol{\beta}}(\mathbf{k})$ and $\mathbf{S}_{\boldsymbol{\alpha}}(\mathbf{k})$ stated in corollary (1) are functions of $\mathbf{k}$

\section{3 - Empirical study}

Samar will be used to investigate, empirically, the bias in horizontal and vertical aggregation of time series. 11 series of 52 weekly income data of 11 farmers in a farm near by. Data were collected through the Egyptian agrarian year.2017/2018, (October 2017 - September 2018).

\subsection{Model building}

The model consists of 11 individual equations

$$
Y_{i T}=\alpha_{i}+\beta_{i} T_{i}+e_{i T} \quad i=1, \ldots, 11 \quad T=1, \ldots, 52
$$

Where:

$$
\mathrm{Y}_{\mathrm{iT}} \quad \text { weekly income of farmer } \mathrm{i}
$$


Scientific Journal for Financial and Commercial Studies and Researches

(SJFCSR) Faculty of Commerce - Damietta University

$\alpha_{i} \quad$ intercept of equation i

$\beta_{\mathrm{i}} \quad$ slope of equation $\mathrm{i}$

$\mathrm{T}_{\mathrm{i}} \quad$ serial number of weeks $1,2, \ldots, 52$

$\mathrm{e}_{\mathrm{iT}} \quad$ random error of equation $\mathrm{i}$

\subsection{Data collection and investigation}

The farmers whose data are collected work together in a farm near by Port Said. Most agrarian ownership in Egypt are small and medium farms, individually owned. Therefore, the Egyptian agriculture is half mechanized. So manual work is a must. Each farmer cares about a certain part of the cultivated area of the farm. He earns a proportion of the harvest against his manual work. This ratio varies from $1 / 4$ or $1 / 3$ or $1 / 2$, each ratio implies different obligations on the farmer.

In our case the farmer earns $1 / 4$ of the harvest, against all the manual work including removing weeds whether manually or using pesticides. The agrarian area is cultivated twice in the agrarian year summer crop, mainly rice, and winter crop mainly wheat.

Thus, income of farmer (1), for instance, consists of his share of farming 5 faddans (faddan is agrarian area unit $=4200 \mathrm{~m}^{2}$ ) as follows

Summer crop (rice) harvested by October 2017 calculated as follows:

5 faddans $\times 3=15$ ton (average productivity 3 ton/faddan)

Share of the farmer $=15 \div 4=3.75$ ton

Subtract 0.75 ton cost of pesticides

Net $=3$ ton $\times$ LE $3500=$ LE 10,500 making LE 404 weekly average (fixed) income through the first half of the year (26 weeks) from October 2017 till March 2018

Winter crop (wheat) harvested by April 2018 calculated as follows:

5 faddans $\times 1.8=9$ ton (average productivity 1.8 ton/faddan)

Share of the farmer $=9 \div 4=2.25$ ton

Subtract 0.25 ton cost of pesticides 


\section{Samar Ahmed Helmy Abdelghany}

Net $=2$ ton $\times \operatorname{LE~} 4050=\operatorname{LE} 9,100$ in addition to LE 4000 his share in the value of the wheat's hay making LE 504 weekly average (fixed) income through the second half of the year (26 weeks) April / September 2018

In addition he works, randomly, for the others for LE 50 daily wage. Some of his family members may work daily besides him too, so a farmer may have more than 7 working days a week.

This system applies to all farmers with two differences:

1 - The area each farmer farms

2 - Number of daily wages earned each week

Data are collected under the direct supervision of the researcher presented in the appendix

Using SPSS-20 to test the data collected, the following table (1) shows that all $\mathrm{Y}^{\prime}$ 's (except $\mathrm{Y}_{3} \& \mathrm{Y}_{4}$ ) are random variables. This means that 9 are non stationary, and the other two are stationary. This fact will be considered through the analysis 
Scientific Journal for Financial and Commercial Studies and Researches

(SJFCSR) Faculty of Commerce - Damietta University

\begin{tabular}{|c|c|c|c|c|}
\hline \multicolumn{5}{|c|}{$\begin{array}{l}\text { Table (2) } \\
\text { Randomness test of the series studied } \\
\text { Hypothesis Test Summary }\end{array}$} \\
\hline & Null Hypothesis & Test & Sig. & Decision \\
\hline 1 & $\begin{array}{l}\text { The distribution of income } 1 \text { is } \\
\text { normal with mean } 377.02 \text { and } \\
\text { standard deviation } 111.53 \text {. }\end{array}$ & $\begin{array}{l}\text { One-Sample } \\
\text { Kolmogorov- } \\
\text { Smirnov Test }\end{array}$ & .209 & $\begin{array}{l}\text { Retain the } \\
\text { null } \\
\text { hypothesis. }\end{array}$ \\
\hline 2 & $\begin{array}{l}\text { The distribution of income } 2 \text { is } \\
\text { normal with mean } 266.48 \text { and } \\
\text { standard deviation } 70.50 \text {. }\end{array}$ & $\begin{array}{l}\text { One-Sample } \\
\text { Kolmogorov- } \\
\text { Smirnov Test }\end{array}$ & .124 & $\begin{array}{l}\text { Retain the } \\
\text { null } \\
\text { hypothesis. }\end{array}$ \\
\hline 3 & $\begin{array}{l}\text { The distribution of income } 3 \text { is } \\
\text { normal with mean } 532.69 \text { and } \\
\text { standard deviation } 108.19 \text {. }\end{array}$ & $\begin{array}{l}\text { One-Sample } \\
\text { Kolmogorov- } \\
\text { Smirnov Test }\end{array}$ & .017 & $\begin{array}{l}\text { Reject the } \\
\text { null } \\
\text { hypothesis. }\end{array}$ \\
\hline 4 & $\begin{array}{l}\text { The distribution of income } 4 \text { is } \\
\text { normal with mean } 230.19 \text { and } \\
\text { standard deviation } 84.60 \text {. }\end{array}$ & $\begin{array}{l}\text { One-Sample } \\
\text { Kolmogorov- } \\
\text { Smirnov Test }\end{array}$ & .046 & $\begin{array}{l}\text { Reject the } \\
\text { null } \\
\text { hypothesis. }\end{array}$ \\
\hline 5 & $\begin{array}{l}\text { The distribution of incomes is } \\
\text { normal with mean } 352.62 \text { and } \\
\text { standard deviation } 121.00 \text {. }\end{array}$ & $\begin{array}{l}\text { One-Sample } \\
\text { Kolmogorov- } \\
\text { Smimov Test }\end{array}$ & .071 & $\begin{array}{l}\text { Retain the } \\
\text { null } \\
\text { hypothesis. }\end{array}$ \\
\hline 6 & $\begin{array}{l}\text { The distribution of income6 is } \\
\text { normal with mean } 422.38 \text { and } \\
\text { standard deviation } 126.07 \text {. }\end{array}$ & $\begin{array}{l}\text { One-Sample } \\
\text { Kolmogorov- } \\
\text { Smirnov Test }\end{array}$ & .371 & $\begin{array}{l}\text { Retain the } \\
\text { null } \\
\text { hypothesis. }\end{array}$ \\
\hline 7 & $\begin{array}{l}\text { The distribution of incmoe } 7 \text { is } \\
\text { normal with mean } 352.35 \text { and } \\
\text { standard deviation } 125.08 \text {. }\end{array}$ & $\begin{array}{l}\text { One-Sample } \\
\text { Kolmogorov- } \\
\text { Smirnov Test }\end{array}$ & .918 & $\begin{array}{l}\text { Retain the } \\
\text { null } \\
\text { hypothesis. }\end{array}$ \\
\hline 8 & $\begin{array}{l}\text { The distribution of income } 8 \text { is } \\
\text { normal with mean } 472.11 \text { and } \\
\text { standard deviation } 116.72 \text {. }\end{array}$ & $\begin{array}{l}\text { One-Sample } \\
\text { Kolmogorov- } \\
\text { Smirnov Test }\end{array}$ & .557 & $\begin{array}{l}\text { Retain the } \\
\text { null } \\
\text { hypothesis. }\end{array}$ \\
\hline 9 & $\begin{array}{l}\text { The distribution of incomeg is } \\
\text { normal with mean } 542.00 \text { and } \\
\text { standard deviation } 154.62 \text {. }\end{array}$ & $\begin{array}{l}\text { One-Sample } \\
\text { Kolmogorov- } \\
\text { Smirnov Test }\end{array}$ & .889 & $\begin{array}{l}\text { Retain the } \\
\text { null } \\
\text { hypothesis. }\end{array}$ \\
\hline 10 & $\begin{array}{l}\text { The distribution of income } 10 \text { is } \\
\text { normal with mean } 656.74 \text { and } \\
\text { standard deviation } 139.53 \text {. }\end{array}$ & $\begin{array}{l}\text { One-Sample } \\
\text { Kolmogorov- } \\
\text { Smimov Test }\end{array}$ & .494 & $\begin{array}{l}\text { Retain the } \\
\text { null } \\
\text { hypothesis. }\end{array}$ \\
\hline 11 & $\begin{array}{l}\text { The distribution of income } 11 \text { is } \\
\text { normal with mean } 626.72 \text { and } \\
\text { standard deviation } 178.09 \text {. }\end{array}$ & $\begin{array}{l}\text { One-Sample } \\
\text { Kolmogorov- } \\
\text { Smirnov Test }\end{array}$ & .428 & $\begin{array}{l}\text { Retain the } \\
\text { null } \\
\text { hypothesis. }\end{array}$ \\
\hline
\end{tabular}

Asymptotic significances are displayed. The significance level is 05 . 


\subsection{Bias in the horizontal aggregation of the series}

Trend of the 11 detailed series is calculated, and that of the horizontally aggregated series. Parameters of the aggregated trend are compared to the sum of the corresponding parameters to calculate the bias.

Working the data of farmer (1) as an example. Coefficients of the trend are shown in table (4). They are significant at $1 \%$ level, where calculated $\mathrm{t}=11.38$ against tabulated $\mathrm{t}_{(51,0.01)} \approx 2.692$. Significance is clear also from column Sig. of table (4) below. So, trend (1) is:

$$
\hat{Y}_{1}=224,3+5,76 \mathrm{~T}
$$

Table (3)

Coefficients of the weekly trend of series (1) of the empirical data

Coefficients $^{\mathrm{a}}$

\begin{tabular}{|c|c|c|c|c|c|c|}
\hline \multirow{2}{*}{\multicolumn{2}{|c|}{ Model }} & \multicolumn{2}{|c|}{ Unstandardized Coefficients } & \multirow{2}{*}{$\begin{array}{c}\begin{array}{c}\text { Standardized } \\
\text { Coefficients }\end{array} \\
\text { Beta }\end{array}$} & \multirow[b]{2}{*}{$t$} & \multirow[b]{2}{*}{ Sig. } \\
\hline & & $\mathrm{B}$ & Std. Error & & & \\
\hline \multirow[t]{2}{*}{1} & (Constant) & 224.274 & 19.708 & & 11.380 & .000 \\
\hline & Time & 5.764 & .647 & .783 & 8.907 & .000 \\
\hline
\end{tabular}

a. Dependent Variable: income1

The same procedure is followed for all series, the result is:

$$
\begin{array}{lll}
\text { Trend (1) } & \hat{Y}_{1}=224,3+5,76 T & \bar{Y}_{1}=377.02 \\
\text { Trend (2) } & \hat{Y}_{2}=184,4+3,10 T & \bar{Y}_{2}=266.48 \\
\text { Trend (3) } & \hat{Y}_{3}=442,6+3,40 T & \bar{Y}_{3}=532.69 \\
\text { Trend (4) } & \hat{Y}_{4}=141,8+3,34 T & \bar{Y}_{4}=230.19 \\
\text { Trend (5) } & Y_{5}=201,6+5,70 T & \bar{Y}_{5}=352.62 \\
\text { Trend (6) } & \hat{Y}_{6}=376,1+1,75 T & \bar{Y}_{6}=422.38 \\
\text { Trend (7) } & \hat{Y}_{7}=359,3(-) 0,26 T & \bar{Y}_{7}=352.35
\end{array}
$$


Scientific Journal for Financial and Commercial Studies and Researches

(SJFCSR) Faculty of Commerce - Damietta University

\begin{tabular}{lc}
\hline \hline Trend (8) & $\hat{Y}_{8}=324,9+5,55 T \quad \bar{Y}_{8}=472.11$ \\
Trend (9) & $\hat{Y}_{9}=339,1+7,66 T \quad \bar{Y}_{9}=542.00$ \\
Trend (10) & $\hat{Y}_{10}=448,9+7,84 T \bar{Y}_{10}=656.74$ \\
Trend (11) & $\hat{Y}_{11}=358,8+10,11 T \bar{Y}_{11}=626.72$ \\
Sum of all trends & $\sum_{i=1}^{11} Y_{i}=3401,8+53,95 T$ \\
Aggregated trend & $\hat{Z}=3401,8+53,95 T$ \\
It is obvious that $\sum_{i=1}^{11} \hat{\beta}_{i}=53.95=\hat{\mathrm{B}}$ and, $\sum_{i=1}^{11} \hat{\alpha}_{i}=r \leqslant \cdot 1 ، \wedge$ where $\hat{\mathrm{A}}$
\end{tabular} assessing unbiasedness of the slope and the intercept. So horizontal aggregation of time series does not involve any bias coping with the theoretical derivations in $\S \mathbf{2 . 1}$

\subsection{Bias in the vertical aggregation of the series}

The Samar theorem showed that bias in the slope $S_{\beta}$ and that in the intercept $S_{\alpha}$ are $f(k)$. So, the available data, 52 observations, will be studied with $\mathrm{k}=2$ and $\mathrm{k}=4$ the only available values for $\mathrm{k}$.

Data are aggregated bi-weekly, $\mathrm{k}=2$ and monthly, $\mathrm{k}=4$. Necessary manipulations are done to compute $\mathrm{S}_{\beta}(\mathrm{k})$ and $\mathrm{S}_{\alpha}(\mathrm{k})$ in both cases of $\mathrm{k}$.

Farmer (1)

Working the series of farmer (1) as an example, weekly trend shown in (3.2) was $\quad \hat{Y}_{1}=224,3+5,76 \mathrm{~T}, \bar{Y}_{1}=377.02$

Bi-weekly trend, i.e $\mathrm{k}=2$ 
Samar Ahmed Helmy Abdelghany

Table (4)

Coefficients of the bi-weekly trend of series (1) of the empirical data

Coefficients $^{\mathrm{a}}$

\begin{tabular}{|c|c|c|c|c|c|}
\hline \multirow{2}{*}{ Model } & \multicolumn{2}{|c|}{$\begin{array}{l}\text { Unstandardized } \\
\text { Coefficients }\end{array}$} & $\begin{array}{l}\text { Standardized } \\
\text { Coefficients }\end{array}$ & \multirow[t]{2}{*}{$\mathrm{t}$} & \multirow{2}{*}{ Sig. } \\
\hline & B & Std. Error & Beta & & \\
\hline (Constant) & 444.083 & 48.148 & & 9.223 & .000 \\
\hline زمن نصف & 22.960 & 3.118 & .833 & 7.364 & .000 \\
\hline
\end{tabular}

a. Dependent Variable: Bi-weekly (1)

Bi-weekly trend $\quad \hat{H}_{1}=444,1+22,96 R$

where $\mathrm{H} \quad$ Biweekly income

R Biweekly time $1,2, \ldots, 26$

Monthly trend, i.e $\mathrm{k}=4$

\section{Table (5)}

Coefficients of the monthly trend of series (1) of the empirical data

\begin{tabular}{|c|c|c|c|c|c|c|}
\hline \multicolumn{7}{|c|}{ Coefficients $^{\mathrm{a}}$} \\
\hline \multirow{2}{*}{\multicolumn{2}{|c|}{ Model }} & \multicolumn{2}{|c|}{$\begin{array}{c}\text { Unstandardized } \\
\text { Coefficients }\end{array}$} & \multirow{2}{*}{$\begin{array}{c}\text { Standardized } \\
\text { Coefficients } \\
\text { Beta } \\
\end{array}$} & \multirow[t]{2}{*}{$\mathrm{t}$} & \multirow[t]{2}{*}{ Sig. } \\
\hline & & B & Std. Error & & & \\
\hline \multirow{2}{*}{1} & (Constant) & 874.077 & 120.011 & & 7.283 & .000 \\
\hline & Time & 90.571 & 15.120 & .875 & 5.990 & .000 \\
\hline
\end{tabular}

دخل شهريa. Dependent Variable:

Monthly trend $\hat{Z}_{1}=874,1+90,57 X$

where $\mathrm{Z} \quad$ Monthly income

R Monthly time $1,2, \ldots, 13$ 


\section{Calculating aggregation bias using Samar}

According to Samar,

aggregation bias in the slope $\quad \mathbf{S}_{\boldsymbol{\beta}}(\mathbf{k})=\hat{\mathrm{B}}-k^{2} \hat{\beta} \quad$ and

aggregation bias in the intercept $\mathbf{S}_{\mathbf{a}}(\mathbf{k})=\hat{\mathrm{A}}-k\left[\bar{Y}-\frac{1}{2} \beta(n+k)\right]$

are computed with $\mathrm{k}=2$, and $\mathrm{k}=4$ and compare the results

Farmer (1) for $\mathrm{k}=2$

Use weekly and bi-weekly parameters and substitute in (3.3) to get:

$\mathbf{S}_{\boldsymbol{\beta}}(\mathbf{2})=22.96-(2)^{2} 5.76=-0.08=-\% 0.35$ of $\hat{B}$

Use weekly and bi-weekly parameters and substitute in (3.4) to get:

$\mathbf{S}_{\boldsymbol{\alpha}}(\mathbf{2})=444.1-2[377.02-1 / 2(5.76)(52+2)]=1.10 .25 \%$ of $\hat{\mathrm{A}}$

For $\mathrm{k}=\varepsilon$

Use weekly and monthly parameters and substitute in (3.4) to get:

$\mathbf{S}_{\boldsymbol{\beta}}(\mathbf{4})=90.57-(4)^{2} 5.76=-1.59=-1.67 \%$ of $\hat{B}$

Use weekly and monthly parameters and substitute in (3.4) to get:

$\mathbf{S}_{\boldsymbol{\alpha}}(\mathbf{4})=874.1-4[377.02-1 / 2(90.57)(52+2)]=11.14=1.27 \%$ of $\hat{\mathrm{A}}$

The same procedure is applied to the remaining series to compute $\mathbf{S}_{\boldsymbol{\beta}}(\mathbf{k})$ and $\mathbf{S}_{\boldsymbol{\alpha}}(\mathbf{k})$, the results are shown in table (5) below 
Samar Ahmed Helmy Abdelghany

Table (6)

Aggregation bias in all series according to $\mathrm{k}$

\begin{tabular}{|c|c|c|c|c|c|c|c|c|}
\hline \multirow{2}{*}{ Series } & \multicolumn{3}{|c|}{ Bias in the slope $\mathbf{S}_{\boldsymbol{\beta}}(\mathbf{k})$} & \multicolumn{3}{c|}{ Bias in the intercept $\mathbf{S}_{\boldsymbol{\alpha}}(\mathbf{k})$} \\
\cline { 2 - 10 } & \multicolumn{2}{|c|}{$\mathrm{k}=2$} & \multicolumn{2}{|c|}{$\mathrm{k}=4$} & \multicolumn{2}{c|}{$\mathrm{k}=2$} & \multicolumn{2}{c|}{$\mathrm{k}=4$} \\
\hline & amount & $\%$ & amount & $\%$ & amount & $\%$ & amount & $\%$ \\
\hline$(1)$ & -0.08 & -0.35 & -1.59 & -1.67 & 1.1 & 0.25 & 11.14 & 1.27 \\
\hline$(2)$ & -0.05 & -0.4 & 0.19 & 0.38 & 0.67 & 0.18 & -1.32 & -0.18 \\
\hline$(3)$ & 0.11 & 0.82 & -1.38 & -2.60 & 1.53 & 0.17 & 9.64 & 0.55 \\
\hline$(4)$ & -0.07 & -0.52 & 0.13 & 0.24 & 1.11 & 0.35 & -0.88 & -0.16 \\
\hline$(5)$ & 0.02 & 0.09 & 0.54 & 0.59 & -0.28 & -0.07 & -3.78 & -0.59 \\
\hline$(6)$ & 0.07 & 0.99 & -0.57 & -2.08 & -0.89 & -0.12 & 3.98 & 0.27 \\
\hline$(7)$ & -0.05 & -4.59 & -0.67 & -13.87 & 0.67 & 0.09 & 4.68 & 0.32 \\
\hline$(8)$ & 0.05 & 0.22 & -0.46 & -0.52 & -0.72 & -0.11 & 3.26 & 0.26 \\
\hline$(9)$ & 0.08 & 0.26 & 0.03 & 0.02 & $1.09-$ & -0.16 & -0.08 & -0.01 \\
\hline$(10)$ & -0.17 & -0.55 & -0.04 & -0.02 & 2.43 & 0.27 & 0.42 & 0.02 \\
\hline$(11)$ & 0.04 & 0.10 & -1.32 & -0.82 & -0.39 & -0.06 & 9.32 & 0.67 \\
\hline $\mathrm{M}$ & -0.005 & -0.357 & -0.467 & -1.85 & 0.523 & 0.072 & 3.307 & 0.22 \\
\hline$|\mathrm{M}|$ & 0.0718 & 0.8082 & 0.6291 & 2.0736 & 0.9891 & 0.1664 & 4.4091 & 0.3909 \\
\hline
\end{tabular}

\section{Results:}

Two different means of the bias are calculated: the usual mean "M" and the mean of the absolute amounts of the bias $|\mathrm{M}|$, call it free mean.

1 - The mean $\mathrm{M}$ of $\mathrm{S}_{\beta}(2)$ i.e $\overline{\mathrm{S}}_{\beta}(2)=-0.005$ while $\overline{\mathrm{S}}_{\beta}(4)=-0.467$ showing the same direction of the bias, but concerning the amount of $\operatorname{bias}\left|\overline{\mathrm{S}}_{\beta}(4)\right|=|-0.467|>\left|\overline{\mathrm{S}}_{\beta}(2)\right|=|-0.005|$

2 - The same argument applies to the mean bias of the intercept. M of $\overline{\mathrm{S}}_{\alpha}(2)=0.523$ while $\overline{\mathrm{S}}_{\alpha}(4)=3.307$ showing the same direction and amount of bias $\overline{\mathrm{S}}_{\alpha}(4)>\overline{\mathrm{S}}_{\alpha}(2)$

3 - The mean $\mathrm{M}$ of the relative bias in $\mathrm{B}$ and $\mathrm{A}$ leads to the same conclusions (1) and (2) above

4 - The free mean of the slope $\mathrm{f} \bar{S}_{\beta}(4)=0.6291>\mathrm{f} \bar{S}_{\beta}(2)=0.0718$. Also $\mathrm{f} \bar{S}_{\alpha}(4)=4.4091>\mathrm{f} \bar{S}_{\alpha}(2)=0.9891$ 
Scientific Journal for Financial and Commercial Studies and Researches

(SJFCSR) Faculty of Commerce - Damietta University

5 - The free mean $|\mathrm{M}|$ of the relative bias in B and A leads to the same conclusions (3) and (4) above

6 - The conclusions (1),..,(5) prove that as $\mathrm{k}$ increases, the bias, increases amount and relatively in the slope and the intercept, i.e $\mathbf{S}_{\boldsymbol{\beta}}(\mathbf{k})$ and $\mathbf{S}_{\boldsymbol{\alpha}}(\mathbf{k})$ are functions of (k) coping with corollary (3) of Samar

7 - At $\mathrm{k}=2$ the average bias $\overline{\mathrm{S}}_{\beta}(2)=-0.005$ in the slope induced average bias in the intercept $\overline{\mathrm{S}}_{\alpha}(2)$ up to 0.523 , at $\mathrm{k}=4$, the average bias in the slope $\overline{\mathrm{S}}_{\alpha}$ (4) (increased) to -0.467 moving the average bias in the intercept $\overline{\mathrm{S}}_{\beta}$ (4) up to 3.307 . The same result is achieved if we work with the free means. This realizes corollary (2) of Samar

8 - The correlation between $\mathrm{S}_{\beta}(2)$ and $\mathrm{S}_{\beta}(4) \operatorname{Corr}\left(\mathrm{S}_{\beta}(2), \mathrm{S}_{\beta}(4)\right)=1$ ensuring that the bias increases with $\mathrm{k}$.

$9-\operatorname{Corr}\left(\mathrm{S}_{\beta}(2), \mathrm{S}_{\alpha}(2)\right)=-0.69$ and $\operatorname{Corr}\left(\mathrm{S}_{\beta}(4), \mathrm{S}_{\alpha}(4)\right)=-0.9999$ showing very strong adverse relation as concluded in (7) above.

The adverse relation between $\mathrm{S}_{\beta}(\mathrm{k})$ and $\mathrm{S}_{\alpha}(\mathrm{k})$ is true because they are changes in the slope and the intercept respectively. Let:

$\mathrm{Y}_{\mathrm{T}}=\alpha+\beta \mathrm{T} \quad \mathrm{T}=1,2, \ldots, \mathrm{n} \quad$ be aggregated on $\mathrm{k}$ and $\mathrm{k}_{1}$, then

$\mathrm{Z}_{\mathrm{X}}=\left\{\mathrm{A}+\mathrm{S}_{\alpha}(\mathrm{k})\right\}+\left\{\mathrm{B}+\mathrm{S}_{\beta}(\mathrm{k})\right\} \mathrm{X}, \quad \mathrm{X}=1,2, \ldots, n / k$

$\mathrm{H}_{\mathrm{R}}=\left\{\delta+\mathrm{S}_{\alpha}\left(\mathrm{k}_{1}\right)\right\}+\left\{\theta+\mathrm{S}_{\beta}\left(\mathrm{k}_{1}\right)\right\} \mathrm{R}, \mathrm{R}=1,2, \ldots, n / k 1$

Since aggregation does not affect the total sum of the series then

$$
\Sigma \mathrm{Y}_{\mathrm{T}}=\Sigma \mathrm{Z}_{\mathrm{X}}=\Sigma \mathrm{H}_{\mathrm{R}}
$$

If $\mathrm{S}_{\alpha}\left(\mathrm{k}_{1}\right)>\mathrm{S}_{\alpha}(\mathrm{k})$ then $\mathrm{S}_{\beta}\left(\mathrm{k}_{1}\right)$ should be less than $\mathrm{S}_{\beta}(\mathrm{k})$ (at some value) and vice versa, to maintain the total sum of the series unchanged. If $S_{\beta}(k)$ and $S_{\alpha}(k)$ went the same direction, the total sum of the series changes. This explains the adverse relation between $S_{\beta}(k)$ and $S_{\alpha}(k)$

Theoretical derivations, and analysis of the case study above prove validity of the Samar theorem. Horizontal aggregation does not produce any bias in the parameters of the trend of the aggregated series. While 
Samar Ahmed Helmy Abdelghany

vertical aggregation implies aggregation bias as expressed in the corollaries of Samar theorem

\section{References}

1 - Albuquerque, Pedro H, 2003. "A practical log-linear aggregation method with examples: heterogeneous income growth in the USA,"Journal of Applied Econometrics, John Wiley \& Sons, Ltd., vol. 18(6), pages 665-678.

2 .- Blundell, R. and Stoker, T. 2005. Aggregation and heterogeneity. Journal of Economic Literature 43, 347-91.

Franta, Michal (2008) "Time aggregation bias in discrete time 3 models of aggregate duration data" Czech National Bank, Prague

4 - Helmy, Samar (2021) "Effect of estimation method on the aggregation bias if one of the regressors is stochastic" (in Arabic) Scientific journal for financial and commercial studies and research, jssub@ekb.eg, July 2021

5 - Moorman, Jeanne E. (1979) Aggregation Bias: An Empirical Demonstration" Sociological Methods \& Research, Vol. 8 No 1, August 1979 69-94@1979 Sage Publications, Inc

6 - Robinson, W.S. (1950) "Ecological Correlations and the Behavior of Individuals," American Sociological Review, Vol. 15, No. 3, 1950, pp. 351-357.

7 - Sbrana, Giacomo, (2011) "Structural Time Series Models and Aggregation: Some Analytical Results" Neoma Business School May 2011

8 - Theil, Henri (1954), Linear Aggregation of Economic Relations, North-Holland, Amsterdam. 
Appendix (1)

Proof of part (2) of Samar theorem, i.e to show that, $\mathbf{B}(\mathbf{k})=\boldsymbol{\beta} \boldsymbol{k}^{2}$

Using the algebraic series $\mathrm{Y}_{\mathrm{T}}=13+3 \mathrm{~T} \quad, \mathrm{~T}=1, \ldots, 60$

For convenience, let $\mathrm{Z}=\mathrm{Z}(\mathrm{k})$ and $\mathrm{X}=\mathrm{X}(\mathrm{k})$ then the aggregated series is

$$
\mathrm{Z}_{\mathrm{X}}=\mathrm{M}+\mathrm{B} \mathrm{X} \quad \mathrm{X}=1, . ., n / k
$$

where $Z_{X}(k)=\sum_{j=1}^{k} Y_{k X-k+j}, X=1, \ldots, n / k, j=1, \ldots, k$

$$
\mathrm{B}=\frac{\sum_{X=1}^{n / k}\left(Z_{X}-\bar{Z}\right)(X-\bar{X})}{\sum_{X=1}^{n / k}(X-\bar{X})^{2}}
$$

Mathematically, if $\mathrm{T}=$ natural numbers $1, \ldots, \mathrm{n}$ its sum $=n / 2(1+\mathrm{n})$. If aggregated on period $k=+$ ve number $<\mathrm{n}$ yields the following arithmetic progression having the same sum

$$
\sum_{j=1}^{k} T_{j}+\mathrm{Xk}^{2}, \mathrm{~T}=1, \ldots, \mathrm{n} \quad \mathrm{X}=0, \ldots,(n / k-1), \mathrm{j}=1, \ldots, \mathrm{k}
$$

if $\mathrm{k}=2$, then

first term $=\sum_{j=1}^{2} T_{j}+\mathrm{Xk}^{2}=1+2+0\left(\mathrm{k}^{2}\right)=3$

to get the last term put $\mathrm{X}=(n / k-1)=n / 2-1$

last term $=\sum_{j=1}^{2} T_{j}+\mathrm{Xk}^{2}=3+(n / 2-1) 4=3+2 \mathrm{n}-4=2 \mathrm{n}-1$ 
sum of the progression $=n / 2 / 2(3+2 n-1)=n / 2(1+n)$ which is the sum of original progression

if $\mathrm{k}=3$, then

first term $=\sum_{j=1}^{3} T_{j}+\mathrm{Xk}^{2}=1+2+3+0\left(\mathrm{k}^{2}\right)=6$

to get the last term put $\mathrm{X}=(n / k-1)=n / 3-1$

last term $=\sum_{j=1}^{3} T_{j}+\mathrm{Xk}^{2}=6+(n / 3-1) 9=6+3 \mathrm{n}-9=3 \mathrm{n}-3$

sum of the progression $=n / 3 / 2(6+3 n-3)=n / 2(1+n)$ which is the sum of original progression

The first term in progression (2) is constant, the term $\mathrm{Xk}^{2}$ is an arithmetic progression, so it suits as regressor for the aggregated series on period $\mathrm{k}$, for convenience, let $\mathrm{Z}=\mathrm{Z}(\mathrm{k})$ and $\mathrm{X}=\mathrm{X}(\mathrm{k})$ then the aggregated series will be $Z=\mathrm{A}+\Delta\left(X k^{2}\right)$

Now, regress it on the time $\mathrm{Xk}^{2}=\mathrm{k}^{2}, 2 \mathrm{k}^{2}, \ldots .(n / k) \mathrm{k}^{2}=\mathrm{nk}$

then $\Delta=\frac{\sum_{x=1}^{n / k}\left(Z_{x}-\bar{Z}\right)\left(X k^{2}-\bar{X} k^{2}\right)}{\sum_{x=1}^{n / k}\left(X k^{2}-\bar{X} k^{2}\right)^{2}}$

for $k=2$ the trend is: $\mathrm{Z}=23+3 \mathrm{Xk}^{2}$

Coefficients of the algebraic equation $Y_{T}=13+3 T$ aggregated on period $\mathrm{k}=2$ and time $\mathrm{Xk}^{2}$ 
Scientific Journal for Financial and Commercial Studies and Researches (SJFCSR) Faculty of Commerce - Damietta University

\begin{tabular}{|c|c|c|c|c|c|c|}
\hline \multicolumn{7}{|c|}{ Coefficients $^{\mathrm{a}}$} \\
\hline & \multirow{2}{*}{ Model } & \multicolumn{2}{|c|}{$\begin{array}{l}\text { Unstandardized } \\
\text { Coefficients }\end{array}$} & \multirow{2}{*}{$\begin{array}{c}\text { Standardized } \\
\text { Coefficients }\end{array}$} & \multirow{2}{*}{$\mathrm{t}$} & \multirow{2}{*}{ Sig. } \\
\hline & & $\mathrm{B}$ & Std. Error & & & \\
\hline \multirow{2}{*}{1} & (Constant) & 23.000 & .000 & & . & \\
\hline & Time $X k^{2}$ & 3.000 & .000 & 1.000 & . & \\
\hline
\end{tabular}

Dependent Variable: $\mathrm{Y}$ aggregated 2

the aggregated slope $\Delta=3$

the intercept $\mathrm{A}=\bar{Z}-\Delta\left(\bar{X} k^{2}\right)=k \bar{Y}-\Delta k^{2}\left(\frac{1}{2}(1+n / k)\right)$

substitute in the right hand side term $A=2(104.5)-3(4)(15.5)=23$

notice that the aggregated slope $\Delta=3$ the slope of the detailed equation and the intercept $=23=$ the intercept of equation (2.15) regressed on time $\mathrm{X}=1,2, \ldots \ldots, 30(\mathrm{n} / \mathrm{k})$

For $k=3$ the trend is $: \mathrm{Z}=30+3 \mathrm{Xk}^{2}$

the aggregated slope $\Delta=3$ the slope of the detailed equation and the intercept $=30=$ the intercept of equation (2.17) regressed on time

$\mathrm{X}=1,2, \ldots \ldots, 20(\mathrm{n} / \mathrm{k})$

For $k=4$ the trend is : $\mathrm{Z}=34+3 \mathrm{Xk}^{2}$

the aggregated slope $\Delta=3$ the slope of the detailed equation and the intercept $=34=$ the intercept of equation (2.19) regressed on time

$\mathrm{X}=1,2, \ldots \ldots, 15(\mathrm{n} / \mathrm{k})$

Which is the same result $\forall k<n$ 
Now, $\Delta=\frac{\sum_{x=1}^{n / k}\left(Z_{x}-\bar{Z}\right)\left(X k^{2}-\bar{X} k^{2}\right)}{\sum_{X=1}^{n / k}\left(X k^{2}-\bar{X} k^{2}\right)^{2}}=$ slope of the detailed equation $\beta$

thus proving that $\quad \mathrm{B}=\Delta \mathrm{k}^{2}$ proves that $\mathrm{B}=\beta \mathrm{k}^{2}$

from equation (1) above $\quad \mathrm{B}=\frac{\sum_{t=1}^{n / k}\left(Z_{t}-\bar{Z}\right)\left(X_{t}-\bar{X}\right)}{\sum_{t=1}^{n / k}\left(X_{t}-\bar{X}\right)^{2}}$

multiply the right side by $\quad \frac{k^{4}}{k^{4}} \quad$ it follows directly that

$$
\mathrm{B}=k^{2} \frac{\sum_{X=1}^{n / k}\left(Z_{X}-\bar{Z}\right)\left(X k^{2}-\bar{X} k^{2}\right)}{\sum_{X=1}^{n / k}\left(X k^{2}-\bar{X} k^{2}\right)^{2}}=k^{2} \Delta=k^{2} \beta
$$


Scientific Journal for Financial and Commercial Studies and Researches (SJFCSR) Faculty of Commerce - Damietta University

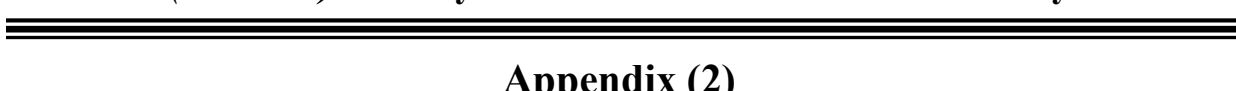

Appendix (2)

Weekly income data of 11 farmers used in the empirical study

\begin{tabular}{|c|c|c|c|c|c|c|c|c|c|c|c|}
\hline $\mathbf{T}$ & $\mathbf{Y}_{1}$ & $\mathbf{Y}_{2}$ & $\mathbf{Y}_{3}$ & $\mathbf{Y}_{4}$ & $\mathbf{Y}_{5}$ & $Y_{6}$ & $\mathbf{Y}_{7}$ & $\mathbf{Y}_{8}$ & $\mathbf{Y}_{9}$ & $Y_{10}$ & $Y_{11}$ \\
\hline 1 & 240 & 240 & 525 & 210 & 400 & 216 & 490 & 380 & 302 & 440 & 412 \\
\hline 2 & 270 & 198 & 450 & 180 & 216 & 550 & 450 & 398 & 205 & 520 & 375 \\
\hline 3 & 325 & 201 & 500 & 150 & 216 & 425 & 350 & 437 & 240 & 420 & 415 \\
\hline 4 & 270 & 201 & 550 & 180 & 216 & 450 & 300 & 416 & 517 & 500 & 359 \\
\hline 5 & 240 & 198 & 475 & 150 & 216 & 450 & 400 & 274 & 682 & 521 & 382 \\
\hline 6 & 350 & 282 & 600 & 210 & 216 & 216 & 400 & 261 & 206 & 660 & 422 \\
\hline 7 & 350 & 228 & 550 & 120 & 216 & 560 & 275 & 298 & 349 & 519 & 517 \\
\hline 8 & 240 & 196 & 450 & 120 & 216 & 216 & 425 & 319 & 599 & 600 & 511 \\
\hline 9 & 270 & 198 & 450 & 180 & 216 & 450 & 450 & 469 & 450 & 522 & 512 \\
\hline 10 & 250 & 201 & 525 & 210 & 216 & 375 & 395 & 354 & 400 & 527 & 417 \\
\hline 11 & 240 & 228 & 525 & 150 & 216 & 540 & 495 & 439 & 367 & 448 & 377 \\
\hline 12 & 400 & 198 & 450 & 120 & 216 & 750 & 385 & 384 & 418 & 496 & 550 \\
\hline 13 & 240 & 168 & 350 & 120 & 216 & 420 & 100 & 357 & 333 & 577 & 530 \\
\hline 14 & 180 & 162 & 275 & 180 & 216 & 520 & 160 & 429 & 472 & 530 & 543 \\
\hline 15 & 270 & 228 & 425 & 180 & 276 & 276 & 100 & 470 & 593 & 423 & 460 \\
\hline 16 & 300 & 228 & 275 & 210 & 306 & 525 & 290 & 385 & 699 & 580 & 681 \\
\hline 17 & 200 & 164 & 250 & 150 & 306 & 250 & 100 & 395 & 564 & 475 & 560 \\
\hline 18 & 225 & 207 & 425 & 180 & 276 & 276 & 230 & 385 & 450 & 500 & 429 \\
\hline 19 & 225 & 168 & 300 & 210 & 306 & 306 & 345 & 460 & 430 & 573 & 477 \\
\hline 20 & 300 & 198 & 625 & 120 & 276 & 276 & 350 & 465 & 370 & 624 & 527 \\
\hline 21 & 325 & 244 & 650 & 150 & 276 & 376 & 275 & 410 & 505 & 539 & 467 \\
\hline 22 & 300 & 243 & 600 & 150 & 246 & 246 & 375 & 450 & 470 & 610 & 585 \\
\hline 23 & 300 & 245 & 625 & 120 & 216 & 216 & 400 & 390 & 416 & 709 & 648 \\
\hline 24 & 350 & 254 & 650 & 150 & 276 & 276 & 425 & 400 & 375 & 685 & 607 \\
\hline 25 & 325 & 243 & 600 & 150 & 246 & 246 & 480 & 390 & 415 & 575 & 350 \\
\hline 26 & 300 & 243 & 625 & 150 & 246 & 246 & 322 & 260 & 450 & 676 & 455 \\
\hline 27 & 500 & 245 & 650 & 150 & 246 & 450 & 230 & 395 & 590 & 713 & 515 \\
\hline 28 & 500 & 265 & 625 & 312 & 560 & 430 & 552 & 450 & 530 & 671 & 572 \\
\hline 29 & 450 & 343 & 500 & 342 & 560 & 420 & 456 & 570 & 625 & 721 & 677 \\
\hline 30 & 475 & 354 & 525 & 372 & 560 & 550 & 422 & 475 & 520 & 832 & 560 \\
\hline 31 & 400 & 264 & 450 & 342 & 530 & 530 & 432 & 390 & 685 & 545 & 690 \\
\hline 32 & 425 & 296 & 575 & 342 & 530 & 550 & 524 & 510 & 537 & 672 & 614 \\
\hline
\end{tabular}


Samar Ahmed Helmy Abdelghany

\begin{tabular}{|c|c|c|c|c|c|c|c|c|c|c|c|}
\hline \hline $\mathbf{T}$ & $\mathbf{Y}_{\mathbf{1}}$ & $\mathbf{Y}_{\mathbf{2}}$ & $\mathbf{Y}_{\mathbf{3}}$ & $\mathbf{Y}_{\mathbf{4}}$ & $\mathbf{Y}_{\mathbf{5}}$ & $\mathbf{Y}_{\mathbf{6}}$ & $\mathbf{Y}_{\mathbf{7}}$ & $\mathbf{Y}_{\mathbf{8}}$ & $\mathbf{Y}_{\mathbf{9}}$ & $\mathbf{Y}_{\mathbf{1 0}}$ & $\mathbf{Y}_{\mathbf{1 1}}$ \\
\hline 33 & 450 & 275 & 450 & 372 & 530 & 540 & 658 & 630 & 607 & 627 & 841 \\
\hline 34 & 400 & 343 & 500 & 342 & 560 & 476 & 540 & 540 & 658 & 712 & 795 \\
\hline 35 & 520 & 272 & 450 & 372 & 530 & 480 & 500 & 475 & 596 & 829 & 815 \\
\hline 36 & 520 & 379 & 650 & 348 & 435 & 435 & 260 & 630 & 658 & 779 & 821 \\
\hline 37 & 375 & 275 & 450 & 318 & 435 & 750 & 100 & 705 & 687 & 816 & 720 \\
\hline 38 & 576 & 354 & 500 & 378 & 405 & 405 & 368 & 690 & 618 & 825 & 747 \\
\hline 39 & 450 & 403 & 625 & 288 & 405 & 405 & 486 & 720 & 559 & 542 & 939 \\
\hline 40 & 576 & 365 & 650 & 318 & 375 & 375 & 290 & 680 & 570 & 846 & 813 \\
\hline 41 & 476 & 403 & 600 & 288 & 435 & 435 & 290 & 450 & 675 & 745 & 868 \\
\hline 42 & 450 & 375 & 625 & 288 & 435 & 435 & 325 & 485 & 670 & 758 & 904 \\
\hline 43 & 450 & 375 & 625 & 288 & 450 & 650 & 268 & 575 & 771 & 803 & 911 \\
\hline 44 & 576 & 386 & 600 & 318 & 450 & 450 & 298 & 560 & 577 & 800 & 819 \\
\hline 45 & 475 & 403 & 600 & 288 & 435 & 460 & 268 & 615 & 537 & 912 & 617 \\
\hline 46 & 450 & 376 & 650 & 288 & 435 & 435 & 268 & 510 & 783 & 855 & 738 \\
\hline 47 & 475 & 275 & 625 & 288 & 450 & 450 & 320 & 525 & 823 & 768 & 850 \\
\hline 48 & 576 & 275 & 625 & 318 & 435 & 460 & 150 & 590 & 686 & 855 & 877 \\
\hline 49 & 450 & 252 & 625 & 210 & 430 & 430 & 375 & 480 & 672 & 849 & 845 \\
\hline 50 & 450 & 244 & 600 & 210 & 460 & 460 & 300 & 520 & 825 & 789 & 750 \\
\hline 51 & 425 & 248 & 600 & 180 & 400 & 450 & 425 & 625 & 780 & 815 & 850 \\
\hline 52 & 450 & 248 & 600 & 210 & 400 & 400 & 450 & 680 & 669 & 825 & 876 \\
\hline
\end{tabular}

